\title{
Interdisciplinary Aspects of Learning: Physics and Psychology
}

\author{
Yavoruk Oleg \\ Department of Physics and Technical Disciplines, Yugra State University, Russia
}

Copyright (C) 2015 by authors, all rights reserved. Authors agree that this article remains permanently open access under the terms of the Creative Commons Attribution License 4.0 International License

\begin{abstract}
The article deals with interdisciplinary aspects of learning in the case of physics and psychology. It describes the lab-based academic course focused on: observation and experimentation; discovery of new scientific facts; measurement; identification of errors; the study of psychological characteristics of people (time perception, the reaction time, thresholds). The above techniques are commonly used by both physicists and psychologists. Students are interested in these topics. They are very important, but are excluded from traditional physics and psychology courses.
\end{abstract}

Keywords Interdisciplinary Learning, Development of Interest, Interdependence, Physics, Psychology

\section{Introduction}

Physics is science that deals with the structure of matter and the interactions between the fundamental constituents of the observable universe [10]. Psychology is scientific discipline that studies mental processes and behavior in humans (and animals). Physics (the basic natural science) elucidates the simplest fundamental questions in nature. Psychology is intimately related to the humanitarian sciences. Physics is concerned with all aspects of nature. Psychology is the science of individual or group behavior [5].

Despite fundamental differences there are the same problems even in so completely different disciplines. Interdisciplinarity is best seen as bringing together distinctive components of two or more disciplines [4].

Interdisciplinary work is often accused of dilettantism and shoddy standards [2]. However, there are many aspects that are included in essence strongly different sciences. Furthermore there are aspects of learning that do not lie within any interdisciplinary science such as psychophysics. Many interdisciplinary issues have a profound philosophical meaning. There are a lot of works with comprehensive defense of interdisciplinary knowledge, research and learning. In pedagogical reality the use of interdisciplinary aspects of science can help for our students to achieve a higher degree of scientifically literacy.

Both experiment and theory play essential and complementary roles in physics. The methods used in psychological research include observation, interviews, psychological testing, laboratory experimentation, statistical analysis, etc. This paper discussion focuses on the study of integrative lab-based (experimental) methods of these sciences.

Experimental tests using humans as subjects involve legal and ethical limitations. This leads to the existence of some procedural difficulties of psychology using in the learning process.

This paper is organized as follows: section 1 includes general information on the described problem; section 2 describes the course and its objectives, where interdisciplinary experiences were applied (subsections 2.1-2.6 detail the project: we show the strategies of our lab-based course articulating student's activities in order to achieve the proposed interdisciplinary objectives); section 3 concerns to the interdisciplinary discussion about research ethics; section 4 describes the impact of this course on students; furthermore in section 5 we provide some concluding and very important remarks. References (section 6) finalize the paper.

\section{Course Description}

Physics is an experimental (natural) science. The primary purpose of these labs is to illustrate some basic principles and methods of experimental physics. We teach students to set goals, determine the values, and calculate the random and systematic errors.

Psychology is experimental (humanitarian) science too. By this reason we have a great opportunity for the psychological characteristics of people use to the study of experimental methods.

Physics teachers and psychologists have a lot of issues for joint discussions, but this research deals only with following interdisciplinary topics: "The Scientific 
Observation"; "The Study of Scientific Facts"; "The Study of Time Perception by Human"; "The Study of Reaction Time (to Light and Sound)"; "The Scarborough's Experiment", "The Difference Threshold").

These labs are intended for use in an introductory physics course at college. Every lab can be completed in 45 minutes. Lab instructions include explanations, questions and calculations that can be used by students. Calculations can be assigned as homework.

\section{The Scientific Observation}

The first lab offered to students is "The Scientific Observation". Observation is an interdisciplinary research method commonly used on the one hand by physicists, chemists, biologists, and on the other hand by psychologists, sociologists, etc. (both natural and humanitarian sciences).

This research technique involves observing objects in their natural environment (Usova, 2002). This method is often used in situations where experimental research is unrealistic. Astronomy is a completely observational science: astronomers obviously cannot do experiments on the heavens.

Observation may be used in contrast with experimentation.

The teacher presents an object or phenomenon to students. The report includes the following sections:

1. Time of the observation and information about the observer.

2. Purpose of the observation (it is formulated by a teacher or chosen by the students).

3. Description of the observing object.

4. Equipment of the observation (it may be selected by students).

5. Conditions of the observation.

6. Description of the observational procedure.

7. Results of the observation.

8. Analysis of results and conclusion from them.

The teacher explains that the plan can be used both in physics and psychology. Then the teacher can ask the following questions about the observation.

1. What features has an observation as a method of scientific research?

2. What is the difference between experimentation and observation?

3. What are the advantages and disadvantages of observation in physics and psychology?

4. What techniques may researchers utilize to collect data of the observation?

5. What are examples of the observation in natural and humanitarian sciences?

\section{The Study of Scientific Facts}

There is nothing in the world that cannot be known through scientific investigation. Scientific knowledge that has been confirmed repeatedly and accepted as true is a scientific fact. A fact is something that has really occurred or is actually the case, a state of affairs. The second lab offered to students is "The Study of Scientific Facts".

We see the following features of the scientific facts that are important for both physics and psychology: 1) objectivity; 2) repeatability (and reproducibility); 3) reliability (credibility).

What should we know about the scientific fact (in natural and humanitarian sciences)? We can use this list.

1. Information about the researcher who discovered the scientific fact;

2. Purposes of the researcher who discovered the scientific fact;

3. Object of his study;

4. Researcher's equipment;

5. Conditions of this study;

6. Description of the detecting procedure;

7. Results of the study, formulation of the scientific fact;

8. Application of the scientific fact.

The Telepathic Abilities Research

In our lab the way to study the features of scientific facts is the experimental study of telepathy human abilities. Telepathy is the direct transference of thoughts from one person (sender) to another (receiver) without the use of ordinary communication channels.

Teacher can be a sender of the signal, and students can be receivers of the signal. The signal of the sender includes two values $\eta=\{0 ; 1\}$. The receiver gets telepathic signals $\xi=\{0$; 1 ) also including the same two values. I recommend 100 tests $(\mathrm{N}=100)$. After the last test the sender dictates to receivers previously sent data $(\eta)$, and students complete the calculation of the results.

Table 1. Results of the Telepathic Abilities Research

\begin{tabular}{|c|c|c|c|}
\hline $\begin{array}{c}\text { Number of the Test } \\
\mathrm{n}\end{array}$ & $\begin{array}{c}\text { Result } \\
\eta=\{0 ; 1\}\end{array}$ & $\begin{array}{c}\text { Result } \\
\xi=\{0 ; 1\}\end{array}$ & $\begin{array}{c}\text { Result } \\
\mathrm{m}\end{array}$ \\
\hline 1 & 1 & 0 & - \\
\hline 2 & 0 & 0 & + \\
\hline$\ldots$ & $\ldots$ & $\ldots$ & $\ldots$ \\
\hline 99 & 0 & 1 & - \\
\hline 100 & 1 & 1 & + \\
\hline \multicolumn{3}{|l}{ Total number of Positive Results M } & 52 \\
\hline
\end{tabular}

Then students calculate the number $M$ of identical values $\eta$ and $\xi$ (fourth column). And finally, on the basis of $\mathrm{P}=\mathrm{M} / \mathrm{N}$ students conclude about the existence of telepathic communication between the sender and the receiver (Table 1).

Students should prepare reports about the scientific fact according to the plan above. Teacher can ask the following questions:

1. What is a scientific fact?

2. What are the features of scientific facts?

3. What do you need to tell if you've discovered a scientific fact? 
4. What value can be determined in this lab?

5. What is the scientific fact you discovered in this lab?

In my experience, the results of this lab always satisfy to the null statistical hypothesis (with small fluctuations $\mathrm{P} \approx 0.50$ ): the null hypothesis might be that there is no relationship between two measured phenomena ( $\eta$ and $\xi$ ) or transference of thoughts has no effect. Conclusion about the continuation of the telepathic abilities research we can do for $\mathrm{P}>0.95$. But unfortunately it never happened in my class.

In this study students can observe fluctuations (small random deviations of a system from its average state).

\section{The Study of Time Perception by Human}

The third lab offered to students is "The Study of Time Perception by Human". Time perception is a field of study within a lot of scientific disciplines: physics, astronomy, psychophysics, philosophy, psychology, etc.

We have a direct (internal) sense of time. It is due to the rhythm of the processes occurring in our body (e.g., pulse, respiration), as well as irreversible biochemical processes in the nervous system.

There are two types of time perception: tachychronia ("accelerated" time sense) and bradychronia ("decelerated" time sense). All people can be divided according to the type of time perception: underestimation and overestimation of time intervals is found in most people (Rubinstein, 2000). However, special training may significantly improve the accuracy of time estimates.

This lab is done in pairs: the experimenter and the tested person. After the measurement they exchange their roles. The task is to determine the duration of the time interval of one minute (60 seconds), relying on an internal sense of time.

Experimenter studies the measuring device (stopwatch), clarifies the rules, the scale and the instrumental error, and then asks: "Are you ready?" The tested person reports on the state of readiness. The experimenter gives the signal to start the test: "Go!" and then watches the stopwatch. The tested person according to the sense of time reports about the expiration of one minute: "Stop!" Experimenter writes the result. In total they must conduct seven such tests. After that they calculate the average time and make an evaluation of the measurement error.

The teacher can ask the following questions:

1. What is time?

2. How do we measure time?

3. What time units do we use?

4. How can we explain "an internal sense of time"?

5. What types of errors can be calculated in the lab?

6. Describe the conditions of your experiment.

\section{The Study of Reaction Time (to Light and Sound)}

Reaction time is the interval between the stimulus and the muscular response to that stimulus. Factors influencing reaction time are gender and age, psychological state, intensity of the stimuli, experience, health, etc. Reaction time is an inherent ability, but it can be improved with practice.
This lab is done in pairs too: the experimenter and the tested person (as in the previous lab). After the measurements they exchange the roles.

We may assess our reactions in the ruler drop test. Experimenter holds the top of a meter ruler. The ruler should be held upright between the hand of the tested partner and the wall. When the experimenter drops the ruler the tested person catches it as quickly as possible. As soon as the tested person sees that it has been dropped, she (or he) presses the ruler and stops its falling. Then the experimenter records how many centimeters the ruler drops before the tested person catches it. The faster the tested person reacts, the less the ruler drops before being caught.

This is a simple way to measure the human reaction time. We have to repeat it seven times and then calculate the average distance the ruler has dropped before the tested person catches it. Knowing the acceleration of gravity (9.8 $\mathrm{m} / \mathrm{s}^{2}$ ) and the distance which flew a meter ruler, we can always find time of catching, i.e. reaction time.

Reaction times are usually closer to $0.20-0.30 \mathrm{~s}$ for a simple visual or sound stimulus. Then students calculate the uncertainty.

This test is performed twice: to measure the reaction time to light and sound signals.

And then the teacher can ask the following questions:

1. What is the sound and light?

2. What is the reaction?

3. What is the reaction time?

4. What factors affect the response time?

5. What is the human reaction time to external stimuli?

6. When is it necessary to know the reaction time?

7. What natural phenomenon is used in the lab?

8. How do you calculate the measurement error?

\section{The Scarborough's Experiment}

The fifth lab (The Scarborough's Experiment) illustrates the origin and behavior of accidental errors. Students should try the following experiment [7].

Experimenter takes a sheet of the paper and draws a line bisecting the space near the middle of the sheet. Then she (or he) puts it on the table or floor and takes a sharp-pointed pencil, holds it by the top between the finger tips and about $40-50 \mathrm{~cm}$ above the paper. After that he (or she) takes a good aim at the line on the paper and tries to hit it by dropping the pencil on it. The pencil should be dropped in this way at least 100 times, making honest efforts to hit the line. The shots will be self-recorded as dots on the paper.

The result of this experiment should be a curve drawn by the students (using as abscissas the distance from the target line to the intervals containing dots and as ordinates the number of dots in the interval). I recommend dividing the whole area of dots into 11 intervals (numbered by $-5,-4,-3$, $-2,-1,0,1,2,3,4,5)$.

The plotted points would have followed the corresponding curve known as the Normal Probability Curve. All kinds of accidental errors follow the same law.

The following facts are true not only in physics but also in 
psychology:

1. Small errors are more frequent than large ones. Probability of an error depends upon its size.

2. Positive and negative errors of the same size are about equal in number.

3. Very large accidental errors occur very rarely.

If we take enough measurements, the effect of the random error normally averages out to nearly zero. Uncertainties are inherent in all measurements and can never be completely eliminated. However, measurements are meaningless without knowledge of their associated errors. We must calculate the uncertainty in the measured quantity for every measurement [1].

Then the teacher can ask the following questions:

1. What illustrates this experiment?

2. What values did you calculate in this lab?

3. What properties of random errors do you know?

4. Why do we need the Normal Probability Curve?

Deviations of the experimental results from the theory (Gaussian distribution) are understood as fluctuations. Fluctuations which students observe in this study may be subject for special explanations of the teacher.

\section{The Difference Threshold}

The sixth lab (The Difference Threshold) allows for students to measure their difference thresholds (differential threshold, just-noticeable difference, difference limen) for the discrimination of line length [8]. Here we use a version of the Method of Constant Stimuli.

In this procedure participant divides the segment $(I=18$ $\mathrm{cm}$ ) in two equal parts using own eye estimation. Of course such a division is always a very approximate: one part of the segment a few millimeters $(\Delta \mathrm{I})$ larger than the other. The test is repeated 10-15 times. Then students calculate the average value, and estimate absolute and relative errors of this quantity.

The calculated value $\Delta \mathrm{I}$ refers to the differential threshold (just-noticeable difference). This approach allows students to calculate the Weber Constant: $\mathrm{k}=\Delta \mathrm{I} / \mathrm{I}$, where $\Delta \mathrm{I}$ represents the difference threshold calculated above, and $\mathrm{I}=18 \mathrm{~cm}$ is the constant stimulus intensity. Using Weber's Law, one could predict the size of the observer's difference threshold for any other intensity value (length of the segment).

Then the teacher can ask the following questions:

1. What is the difference threshold?

2. Why do we need to know the difference thresholds?

3. What determines the difference threshold?

4. Where we could apply the Weber's Law?

Determination of these psychological characteristics enables the teacher to demonstrate all the features of a typical physical experiment.

\section{Discussion about Research Ethics}

Execution of our labs raises the problem concerning subjects who will participate in the study. It gives the opportunity to discuss with students interdisciplinary issues of research ethics. The fact is that science discoveries are neither moral nor immoral. However, researchers (people) can give them a different assessment (for instance, positive or negative).

Experimenters and tested persons in all our labs are students. All labs are executed in pairs. Although the labs do not contain any risk, some participants may be very sensitive to the detection results [3]. Students should be informed that the measured quantities are related to their psychological characteristics. By this reason, their participation in such labs is entirely unforced. Teacher also guarantees anonymity and confidentiality of the experimental results.

Here it is appropriate to consider other aspects of researcher's ethics: fraud in science, plagiarism, responsible for the results.

Then the teacher can offer to discuss the following interdisciplinary questions:

1. What ethical principles we should follow in our labs?

2. What danger is plagiarism in science and education?

3. Are there useful or harmless forms of deception in science, education, everyday life?

4. What labs would you have not advised to other students?

5. What labs were most useful and informative for you?

The results of the answers to the last question presented in Fig. 1. As "The most useful and informative lab" students chose "The Study of Time Perception by Human" (14 participants with a total number of students in the experimental group - 45 , see next section).
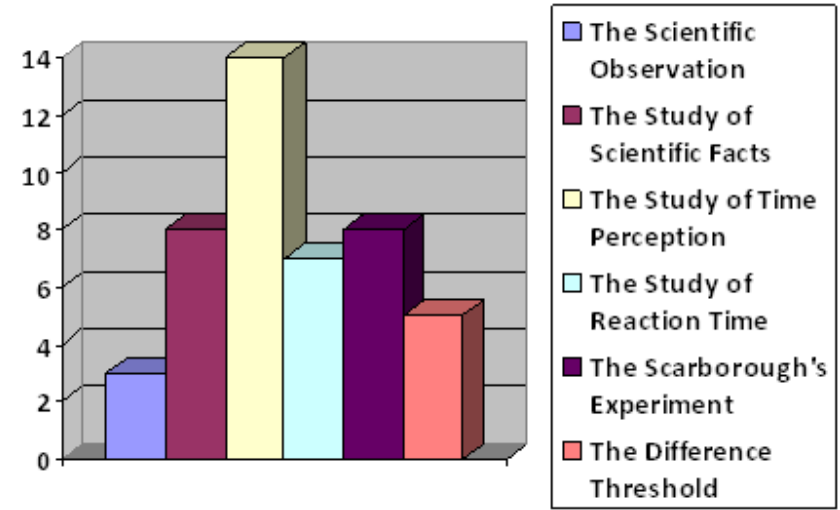

Figure 1. What labs were most useful and informative to you?

\section{Impact on Students' Interest}

In 2011-2012 we ran a pilot to explore how our labs affect the interest of students in learning physics. Students were asked to assess their level of interest in physics ( 0 or 1 or 2 points). 0 (low level) means no interest in physics, 1 (normal level) means the average interest, 2 (advanced level) shows the maximum interest. We chose a group of students roughly equal in achievements and abilities. 
We investigated four academic groups of students: two control academic groups (47 participants) and two experimental ones (45 participants). Students of the experimental group studied the course. Students of the control group did not study the above labs. Certainly all students studied traditional physics course.

We asked the students to answer the questionnaire before and after the study of our labs. Results of the questionnaire are shown in Tables 2 and 3.

Table 2. Results of the questionnaire (before studying the course)

\begin{tabular}{|c|c|c|c|c|c|}
\hline \multicolumn{2}{|c|}{ Groups } & $\begin{array}{c}\text { Total } \\
\text { numbers } \\
\text { of } \\
\text { respondents }\end{array}$ & $\begin{array}{c}\text { Level } \\
0 \\
\text { (Low) }\end{array}$ & $\begin{array}{c}\text { Level 1 } \\
\text { (Normal) }\end{array}$ & $\begin{array}{c}\text { Level 2 } \\
\text { (Advanced) }\end{array}$ \\
\hline \multirow{2}{*}{ Groups } & Control & 47 & 16 & 26 & 5 \\
\cline { 2 - 6 } & Experimental & 45 & 14 & 28 & 3 \\
\hline
\end{tabular}

Table 3. Results of the questionnaire (after studying the course)

\begin{tabular}{|c|c|c|c|c|c|}
\hline \multicolumn{2}{|c|}{ Groups } & $\begin{array}{c}\text { Total } \\
\text { numbers } \\
\text { of } \\
\text { respondents }\end{array}$ & $\begin{array}{c}\text { Level } \\
0 \\
\text { (Low) }\end{array}$ & $\begin{array}{c}\text { Level 1 } \\
\text { (Normal) }\end{array}$ & $\begin{array}{c}\text { Level 2 } \\
\text { (Advanced) }\end{array}$ \\
\hline \multirow{3}{*}{ Groups } & Control & 47 & 12 & 29 & 6 \\
\cline { 2 - 6 } & Experimental & 45 & 2 & 30 & 13 \\
\hline
\end{tabular}

During the study period in all groups there were changes for the better. In the control groups 4 students went from zero (low) level to the first (normal) level; one student from the first (normal) level went to the second (advanced) level. In the experimental groups the change was more radical: from zero (low) level to the first (normal) level 12 students moved, and from the first (normal) level to the second (advanced) level moved 10 students.

\section{Conclusions}

Interdisciplinarity is the distinguishing feature of modern science. There are many interdisciplinary issues that can only be solved by several disciplines together. These are very topical issues and they are always very interesting to young people. The use of psychological characteristics of people in the study of experimental methods leads to the sharp increase of interest to the study of physics. But physicists and psychologists have never met in the classroom; they discuss different issues without affecting overall.

For young people the most interesting problems are associated with radically different branches of knowledge, such as physics and psychology. In our cases, the solution of the interest problem by the interdisciplinary course use is more effectively than by disciplinary one only. Students are extremely attracted by unusual labs and their results.

The study of nature is a very complicated process, and sometimes it is very difficult to tell exactly to which area the source of the problem belongs: physics or psychology. This is also true of such research techniques as observation, discovery of new scientific facts, measurement, identification of errors. These issues are very important, but are excluded from classical physics and psychology courses. Students get acquainted with them, performing the above interdisciplinary labs.

\section{REFERENCES}

[1] Drosg, M. (2009). Dealing with uncertainties: a guide to error analysis. Second Edition, Springer.

[2] Frodeman, R. (2010). The Oxford handbook of interdisciplinarity. New York: Oxford University Press. (236 $-237)$.

[3] Myers, A., Hansen, C. (2012). Experimental psychology. 7th Edition. Publisher/Executive Editor: Linda Schreiber-Ganster.

[4] Nissani, M. (1997). Ten cheers for interdisciplinarity: the case for interdisciplinary knowledge and research. The Social Science Journal, 34(2), 201-216

[5] Psychology. (2009). Encyclopædia Britannica. Encyclopædia Britannica 2009 Ultimate Reference Suite. Chicago: Encyclopædia Britannica.

[6] Rubinstein, S.L. (2000). Osnovy obshchey psikhologii. $\mathrm{SPb}$.: Izdatel'stvo «Piter».

[7] Scarborough, J. B. (1966). Numerical mathematical analysis. Baltimore, Published by Johns Hopkins Press, (Chapter XIX).

[8] Schieber, F. (2013). Weber's law of just noticeable differences (USD Internet Sensation \& Perception Laboratory). Retrieved April 62014 from Web Site http://apps.usd.edu/coglab/WebersLaw.html

[9] Usova, A.V. (2002). Teoriya i metodika obucheniya fizike. Obshie voprosy. SPb. Izd-vo "Meduza".

[10] Weidner, R.T., Brown, L.M. (2009). Physics. Encyclopædia Britannica. Encyclopædia Britannica 2009 Ultimate Reference Suite. Chicago: Encyclopædia Britannica. 